\title{
Alcohol metabolism and health hazards associated with alcohol abuse in a South African context: a review
}

\author{
${ }^{a}$ Pisa PT, PhD a,b Loots Du T, PhD a Nienaber C, PhD \\ ${ }^{a}$ Centre of Excellence for Nutrition, North-West University, Potchefstroom, \\ ${ }^{b}$ Centre for Human Metabonomics, School of Physical and Chemical Sciences, North-West University, Potchefstroom \\ Correspondence to: Dr Pedro Pisa, e-mail: 20369190@nwu.ac.za/pedropisa2005@yahoo.com \\ Key words: alcohol metabolism; teratogenic effects; binge drinking; South Africa
}

\section{Abstract}

The World Health Organization recently stated that alcohol consumption is the fifth leading cause of death worldwide and that intakes are increasing, especially in developing countries. Alcohol-related effects are major threats to global public health. There is growing recognition of an association between alcohol abuse and a host of health and social problems in many parts of the world. In South Africa, a developing country with a rapidly growing economy, available evidence shows that alcohol is a leading risk factor for mortality and morbidity, and hence a significant contributor to the burden of disease. The observed pattern of binge drinking of about a third of South African drinkers is of concern. In addition to physical dependence on alcohol, other psychological, genetic and social factors may contribute to the development of alcohol-related diseases. To develop a relevant, integrated and coherent strategy to address alcohol use, misuse and abuse in South Africa, we need a much better understanding of the metabolism of alcohol, and how the metabolic products and changes associated with alcohol abuse ultimately lead to biological health hazards. This review offers a broad understanding of the metabolism of alcohol and the biological health hazards associated with its abuse. Levels of foetal alcohol syndrome in South Africa are the highest ever recorded, and hence this review will separately address teratogenic effects associated with abuse.

(P) Peer reviewed. (Submitted: 2008-08-12, Accepted: 2010-04-05). ๑ SAJCN

S Afr J Clin Nutr 2010;23(3)(Supplement 1):S4-S10

\section{Introduction}

Alcohol (ethanol) containing beverages are one of the most consumed beverages in Africa. ${ }^{1}$ Ethanol, also called ethyl alcohol, has an energy value of 29.2 kilojoules/gram (7.1 kilocalories/gram) ${ }^{2}$ and is made by fermenting and then distilling starch and sugar crops (maize, sorghum, potatoes, wheat, grapes, sugar cane, and even cornstalks, and fruit and vegetable waste).

There are large individual variations in the absorption, distribution and elimination of alcohol. ${ }^{3}$ Once absorbed, alcohol spreads throughout the body water (alcohol moves easily through cell membranes). The appearance of alcohol in the blood is not related only to the amount of alcohol consumed, but also to various factors affecting alcohol metabolism. These include gender, concentration of alcohol in the beverage, body composition, medication use, genetics, ethnic variations in alcohol metabolism, and the amount and type of food consumed prior to alcohol consumption. ${ }^{3}$

Most of the ingested alcohol is readily absorbed unchanged from the gastrointestinal tract and is one of the few substances readily absorbed from the stomach. Since alcohol is toxic in high amounts, the body attempts to get rid of it as quickly as possible by excreting the unchanged ethanol, or its metabolites. ${ }^{4}$
Most of the ingested ethanol is metabolised in the liver, ${ }^{4}$ although a small amount is metabolised as it passes through the gut. Two major enzyme systems, namely the oxidative and non-oxidative pathways, mediate the initial phase of ethanol metabolism. ${ }^{4,5}$

In 2004 the World Health Organization (WHO) ${ }^{1}$ estimated that about two billion people worldwide consume alcoholic beverages and 76.3 million have diagnosable alcohol disorders. Thus the global burden of alcohol abuse both in terms of mortality and morbidity is considerable throughout the world. ${ }^{1}$ South African drinkers are among the leading consumers of alcohol in the world. What is of greater concern is that the majority of those reported to drink consume huge amounts of alcohol (20 litres of absolute alcohol per drinker per year), ${ }^{6}$ characterising a condition termed 'binge drinking'. The major adverse health effects associated with alcohol abuse are divided into biological health hazards (alcoholic liver disease, alcoholic pancreatitis, cancers, malnutrition, cardiac disorders, gastric complications, neurological disorders) and teratogenic effects.

In this paper we review the metabolism of alcohol and the biological health hazards associated with alcohol abuse in a South African context. 


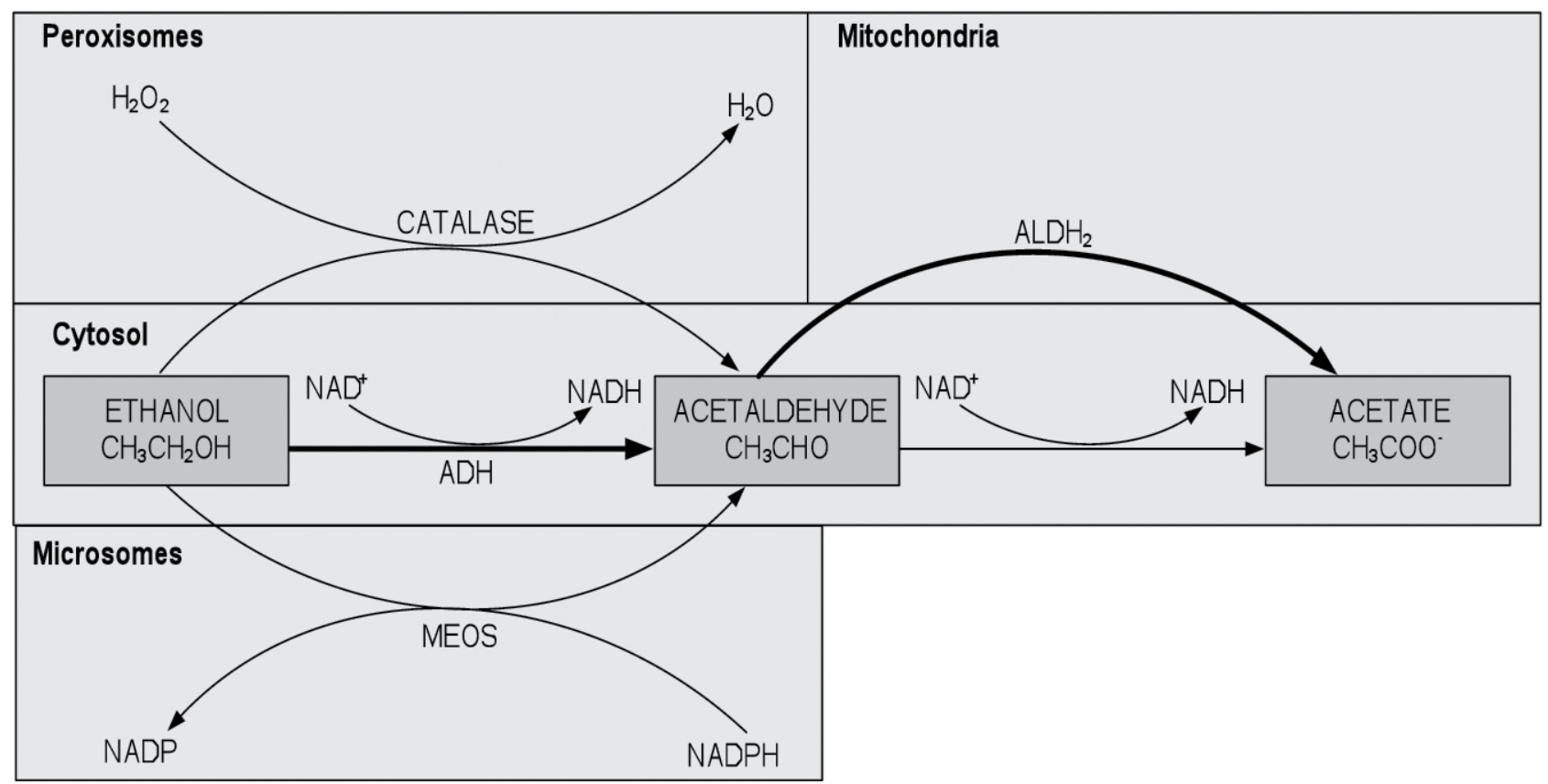

Figure 1: Metabolism of ethanol

ADH: alcohol dehydrogenase; $\mathrm{ALDH}_{2}$ : acetaldehyde dehydrogenase; $\mathrm{H}_{2} \mathrm{O}$ : water; $\mathrm{H}_{2} \mathrm{O}_{2}$ : hydrogen peroxide; MEOS: microsomal ethanol oxidising system; $\mathrm{NAD}^{+}$: nicotinamide adenine dinucleotide; NADH: reduced nicotinamide adenine dinucleotide; NADP: nicotinamide adenine dinucleotide phosphate

\section{Alcohol metabolism}

Alcohol is metabolised via oxidative and non-oxidative processes. The oxidative metabolism of alcohol is a chemical process in which oxygen is used to make energy from ethanol, whilst in non-oxidative metabolism this is accomplished in the absence of oxygen. Oxidative metabolism is accomplished by alcohol dehydrogenase (ADH), the microsomal ethanol oxidising system (MEOS), the catalase enzyme located in the peroxisomes, or first-pass metabolism. First-pass metabolism is defined as the metabolism of orally administered alcohol by gastrointestinal and hepatic enzymes, resulting in a significant reduction of the amount of unmetabolised alcohol reaching the systemic circulation.

\section{Oxidative metabolism of alcohol}

In the hepatocyte there are three oxidative pathways responsible for ethanol metabolism (see Figure 1) and these pathways are located in three different compartments: (1) ADH and members of the cytochrome P450 system (predominately CYP2E1 [cytochrome P450 monoxygenases]) located in the cytosol, ${ }^{5,7,8}$ (2) the MEOS situated in the endoplasmic reticulum, and (3) catalase located in the peroxisomes. In each of these systems pathways ethanol is metabolised to the highly reactive metabolite acetaldehyde. Due to the toxicity of acetaldehyde, the body quickly converts it to acetate in a second oxidation step by mitochondrial acetaldehyde dehydrogenase (ALDH). Finally, the acetate produced in the liver is released into the blood and it is oxidised by peripheral tissues via the Krebs cycle to carbon dioxide, fatty acids and water. ${ }^{9}$

\section{The alcohol dehydrogenase (ADH) system}

Human ADH is a zinc-containing enzyme located almost exclusively in the cytosol of cells. The highest $\mathrm{ADH}$ concentrations (approximately
$80-90 \%$ of the total ADH activity in human tissue) are found in the liver. ADH activity has also been detected in other tissues such as the gut, kidneys and lungs. For the ADH reaction, oxidised nicotinamide adenine dinucleotide $\left(\mathrm{NAD}^{+}\right)$is needed, and $\mathrm{NADH}$ (the reduced form of $\mathrm{NAD}^{+}$) is produced in the cytosol. This results in an increased $N A D H / N A D^{+}$ratio in the cytosol, with a marked shift in the redox potential. ${ }^{10}$ This redox imbalance is responsible for a series of metabolic changes, causing damage to various organs. Acidosis is increased by hyperlactacidaemia and this reduces the capacity of the kidney to excrete uric acid, leading to hyperuricaemia (see Figure 2).

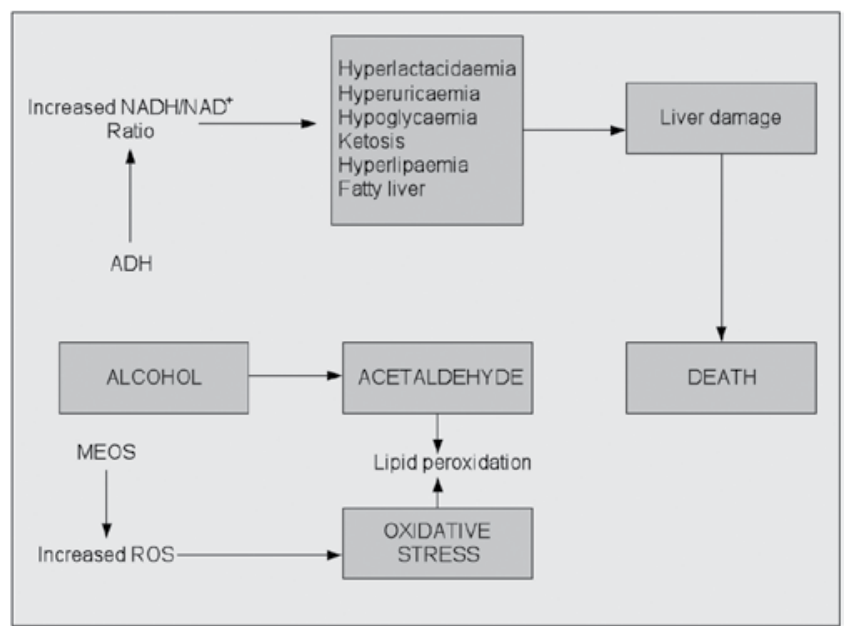

Figure 2: Metabolic changes (hepatic) associated with alcohol metabolism ADH: alcohol dehydrogenase; MEOS: microsomal ethanol oxidising system; NAD+. nicotinamide adenine dinucleotide; $\mathrm{NADH}$ : reduced nicotinamide adenine dinucleotide; ROS: reactive oxygen species 
The increased NADH/NAD+ ratio also leads to an increase in the concentration of $\alpha$-glycerophosphate, which in turn favours the deposition of triglycerides in the liver. Furthermore, excess NADH also favours fatty acid synthesis and accumulation in the liver in the form of triglycerides. The mechanisms by which this is thought to occur are increased hepatic synthesis, decreased hepatic lipoprotein secretion, a greater mobilisation of fatty acids from adipose tissue favouring their hepatic uptake, and a decrease in fatty acid oxidation. ${ }^{11}$ In individuals with depleted glycogen deposits or those who have pre-existing abnormalities in carbohydrate metabolism, alcohol intoxification may cause severe hypoglycaemia due to a blockage of gluconeogenesis by the increased NADH/NAD ${ }^{+}$ratio. ${ }^{11}$

\section{Microsomal ethanol oxidising system (MEOS)}

The MEOS constitutes a second pathway by which alcohol is oxidised. MEOS shares many properties with other microsomal metabolising components, such as cytochrome P-450, reduced nicotinamide adenine dinucleotide phosphate (NADPH) and oxygen. An increase in MEOS activity is usually due to chronic alcohol consumption and this in turn affects CYP2E1, which is the ethanol-inducible form of cytochrome P-450. ${ }^{12}$ This phenomenon could be responsible for the metabolic tolerance of alcoholics to ethanol. Although CYP2E1 has a high capacity for metabolising ethanol, it also has the capacity for activating other hepatotoxic agents, ${ }^{12}$ consequently contributing to liver damage. Furthermore, the high redox potential of CYP2E1 for nicotinamide adenine dinucleotide phosphate (NADP) as a cofactor leads to the formation of free oxygen radicals, oxidative stress and lipid peroxidation, ${ }^{13}$ as indicated in Figure 2. Apart from the obvious consequences of oxidative stress on cardiovascular disease (CVD), atherosclerosis, diabetes and cancers, it also activates the Kupffer cells. Activation of these by oxidative stress increases the expression of cytokines, such as tumour necrosis factor and interleukins, which in turn lead to the activation of stellate cells with consequent increases in collagen synthesis, favouring alcoholic liver disease. ${ }^{14}$

\section{Catalase oxidative system}

The third oxidative pathway in which ethanol is converted to acetaldehyde is by means of the enzyme catalase present in peroxisomes of the liver. Catalase, however, plays a very small role in alcohol metabolism. ${ }^{5}$ In vitro catalase is capable of oxidising ethanol in the presence of a system that generates hydrogen peroxide, but physiologically the rate of alcohol metabolism by this system is reduced by the addition of fatty acids. The $\beta$-oxidation of fatty acids is inhibited by the NADH generated during alcohol metabolism by $\mathrm{ADH}$, and thus inhibition of hydrogen peroxide production occurs, leading to significantly diminished rates of peroxidation of alcohols via catalase..$^{15}$

\section{First-pass metabolism}

There is ample evidence that the stomach plays a role in the oxidative metabolism of ethanol. The presence of class I, III and IV ADH isoenzymes for ethanol in the human stomach has been reported. ${ }^{16-18}$ Intravenous administration of a low dose of ethanol results in higher blood ethanol concentrations than an oral intake of the same amount of ethanol. This has been well demonstrated in human and rat studies, and indicates that part of the ingested ethanol will be metabolised before reaching the peripheral blood, as absorption of ethanol from the gastrointestinal tract is virtually unprohibited. This is known as first-pass metabolism and can theoretically occur in the liver, stomach or intestines. ${ }^{19,20}$ Caballeria et $\mathrm{al}^{21}$ further describe evidence for first-pass metabolism. They reported ADH isoenzyme activity in the gastric mucosa and also showed that first-pass metabolism disappears in patients undergoing gastrectomy, when gastric emptying is accelerated or when alcohol is administered to the duodenum. ${ }^{21}$ Caballeria et al ${ }^{22}$ later confirmed this observation in gastrectomised patients. Blood ethanol concentrations were approximately the same after oral intake and after intravenous infusion of ethanol in these patients. They also showed that in healthy men intraduodenal infusion of ethanol results in significantly higher blood ethanol concentrations than an oral intake of ethanol, which also suggested that by bypassing the stomach first-pass metabolism is reduced. Colonic bacteria (human flora) have been shown to contain high $\mathrm{ADH}$ activity and produce acetaldehyde after ethanol breakdown. ${ }^{23} \mathrm{~A}$ bacteriocolonic pathway for alcohol metabolism has been suggested, with the acetaldehyde produced ultimately being broken down to acetate by bacterial ALDH. ${ }^{24}$ Due to low activity of the ALDH in the colon, accumulation of acetaldehyde can occur during ethanol oxidation. This is one of the factors that contribute to the pathogenesis of alcohol-related gastrointestinal disease. ${ }^{24}$

Ethnic variations in gastric $\mathrm{ADH}$ levels have been reported and are implicated to contribute to the differences observed in ethnic alcohol tolerance and toxicity. Most Caucasians are reported to have $\alpha-A D H$ while most Asians have very low or undetectable activity, causing the first-pass metabolism to be significantly reduced in the latter population group. ${ }^{20}$ Frezza et al ${ }^{25}$ reported that the activity of stomach ADH is lower in women than in men. However, this result is not consistent, as other studies have reported no significant differences between men and women, ${ }^{26}$ and in individuals below the age of $50 . .^{27}$

\section{Non-oxidative metabolism of alcohol}

A non-oxidative pathway for alcohol metabolism in which fatty acid ethyl esters are formed from alcohol has been proposed. ${ }^{28}$ Evidence for this is seen in intoxicated subjects having significantly elevated concentrations of fatty acid ethyl esters (FAEEs) in various organs, such as the brain, liver and heart, and which are thought to result in the alcohol-induced lesions in these organs ${ }^{3}$ FAEEs result from the reaction of alcohol (ethanol) with free fatty acids. These FAEEs can be detected in serum and other body tissue after alcohol ingestion and can persist long after alcohol is eliminated. The effect of FAEEs on alcohol-induced tissue damage remains unclear. ${ }^{28}$ 


\section{Alcohol elimination (excretion)}

Most ethanol (90-98\%) is eliminated from the body by oxidation via various enzyme systems to carbon dioxide and water. The remaining ethanol is excreted by the lungs (1-5\%) through expiration and $1-3 \%$ is excreted via other routes, such as urine $(0.5-2.0 \%)$ and sweat (up to $0.5 \%)^{29}$

Furthermore, increased tolerance to alcohol is displayed by chronic alcoholics. This is due to an increase in the ethanol elimination rate or metabolic tolerance, and due to the adaptation of the central nervous system to alcohol. ${ }^{30}$ The causes of increased metabolic tolerance include increased ADH activity, increased mitochondrial reoxidation of $\mathrm{NADH}$, a hypermetabolic state in the liver, increased microsomal oxidation and increased catalase activity. ${ }^{24}$ Alcohol metabolism is also affected by the nutritional status of an individual, since malnutrition (under-nutrition) diminishes ADH activity, similar to what occurs during high alcohol consumption. ${ }^{31}$

\section{Pathogenic and teratogenic effects associated with alcohol abuse}

\section{Pathogenic effects}

Metabolic changes associated with alcohol abuse ultimately lead to a number of biological health hazards. These have recently been summarised by Van Heerden and Parry ${ }^{32}$ and are shown in Table I.

Alcohol affects the central nervous system of the body more so than any other system. Furthermore, ethanol acts as a central nervous system depressant. ${ }^{33}$ Normal brain development in humans can be impaired by the consumption of large amounts of alcohol. An unusual complication of acute alcohol ingestion is Wernicke's encephalopathy (WE). It is a syndrome characterised by acute confusion, ataxia and eye movement abnormalities (opthalmoplegia and nystagmus). ${ }^{34,35}$ It is caused by an inadequate intake or absorption of thiamine, causing lesions in the medial thalamic nuclei, mamillary bodies, periaqueductal and periventricular brainstem nuclei, and superior cerebellar vermis. ${ }^{35}$ Failure to treat WE leads to an irreversible chronic form of the disease (Korsakoff psychosis), which is characterised by severe short-term memory loss. ${ }^{35,36}$ Twenty-five percent of chronic alcoholics may have peripheral neuropathy, including autonomic disorders ${ }^{37}$ and nearly half may have myopathy. ${ }^{38}$

A common after-effect of ethanol intoxication is the unpleasant sensation known as a hangover, which is partly due to the dehydrating effect of ethanol. Ethanol is known to mitigate the production of the antidiuretic hormone ${ }^{39}$ which is a hormone that acts on the kidney, favouring water reabsorption in the kidneys during filtration.

Alcohol affects many organs, most notably the liver, causing both acute and chronic liver disease. ${ }^{2,4}$ In the liver, ethanol can lead to three distinct pathological disorders, namely a fatty liver (alcoholassociated hepatic steatosis), alcoholic hepatitis and cirrhosis. Alcohol-associated hepatic steatosis is the most common form of liver injury but it is reversible with abstinence. ${ }^{40,41}$ Alcoholic hepatitis is characterised by inflammation of the liver, and cirrhosis by progressive hepatic fibrosis. These are the more serious forms of alcoholic liver disease. ${ }^{42}$
Table I: Summary of health hazards associated with alcohol abuse*

\begin{tabular}{|c|c|}
\hline Nervous system & $\begin{array}{l}\text { Acute intoxication: 'hangovers' and blackouts } \\
\text { Persistent brain damage: Wernicke's encephalopathy, } \\
\text { Korsakoff's syndrome, cerebellar degeneration }\end{array}$ \\
\hline $\begin{array}{l}\text { Cerobrovascular } \\
\text { disease }\end{array}$ & $\begin{array}{l}\text { Strokes, particularly in young people } \\
\text { Subarachnoid haemorrhage } \\
\text { Subdural haematoma following cranial injury } \\
\text { Withdrawal symptoms: tremor, hallucinations, fits } \\
\text { Nerve and muscle damage: weakness, paralysis, 'burning } \\
\text { sensation in extremities' }\end{array}$ \\
\hline Liver & $\begin{array}{l}\text { Fatty infiltration } \\
\text { Alcoholic hepatitis } \\
\text { Cirrhosis leading to liver failure } \\
\text { Liver cancer }\end{array}$ \\
\hline $\begin{array}{l}\text { Gastrointestinal } \\
\text { system }\end{array}$ & $\begin{array}{l}\text { Acid reflux } \\
\text { Tearing/rupture of oesophagus } \\
\text { Cancer of the oesophagus } \\
\text { Gastritis } \\
\text { Aggravation and impaired absorption of food } \\
\text { Chronic inflammation of the pancreas which may lead to } \\
\text { diabetes and malabsorption of food }\end{array}$ \\
\hline Nutrition & $\begin{array}{l}\text { Malnutrition due to reduced food intake, toxic effects of } \\
\text { alcohol on the gastrointestinal tract, impaired metabolism } \\
\text { leading to weight loss, obesity - particularly in the early } \\
\text { stages of heavy drinking }\end{array}$ \\
\hline $\begin{array}{l}\text { Heart and } \\
\text { circulation }\end{array}$ & $\begin{array}{l}\text { Arrhythmias } \\
\text { Hypertension } \\
\text { Chronic damage to cardiac muscle leading to heart failure }\end{array}$ \\
\hline $\begin{array}{l}\text { Respiratory } \\
\text { system }\end{array}$ & Pneumonia from inhalation of vomit \\
\hline $\begin{array}{l}\text { Endocrine } \\
\text { system }\end{array}$ & $\begin{array}{l}\text { Increased production of cortisol leading to obesity, acne, } \\
\text { hirsutism, hypertension } \\
\text { Condition mimicking hyperthyroidism, with weight loss, } \\
\text { anxiety, palpitations, sweating, tremor } \\
\text { Severe hypoglycaemia resulting in coma } \\
\text { Intense facial flushing in diabetes when using } \\
\text { chlorpropamide }\end{array}$ \\
\hline $\begin{array}{l}\text { Reproductive } \\
\text { system }\end{array}$ & $\begin{array}{l}\text { Men: loss of libido, impotence, testicular and penile } \\
\text { shrinkage, loss of sexual hair } \\
\text { Women: menstrual irregularities, shrinkage of breasts and } \\
\text { external genitalia }\end{array}$ \\
\hline $\begin{array}{l}\text { Foetal } \\
\text { development } \\
\text { and teratogenic } \\
\text { effects }\end{array}$ & $\begin{array}{l}\text { Foetal alcohol effects: alcohol-related birth defects, alcohol- } \\
\text { related neurodevelopmental disorders, and foetal alcohol } \\
\text { spectrum defects }\end{array}$ \\
\hline
\end{tabular}

The fibrogenic effects of ethanol and its metabolites on hepatic stellate cells (HSC) ${ }^{42,43}$ include changes in cellular activation such as increased collagen and deoxyribonucleic acid (DNA) synthesis, ${ }^{44}$ increased expression of $\alpha$-smooth muscle actin and depletion of retinyl palmitate. ${ }^{45}$ These manifestations ultimately increase fibrosis. Ethanol and acetaldehyde additionally increase fibrosis by increasing autocrine transforming growth factor beta-1 (TGF $\beta$-1) expression in HSCs. In turn, TGF $\beta$ - 1 is able to upregulate type 1 collagen gene expression. $^{46-48}$

Oxidative stress tends to increase in both chronic and acute ethanol administration. ${ }^{49}$ Within the hepatocyte, ethanol-induced oxidative stress occurs acutely through ethanol metabolism or chronically following the induction of CYP2E1. ${ }^{2,50}$ CYP2E1 has been shown to 
generate ROS, including the superoxide anion, hydrogen peroxide and hydroxyethyl free radicals. ${ }^{2,51}$ Oxidative stress further activates HSC in alcoholic liver fibrogenesis, as human HSC collagen synthesis is induced by 4-hydroxynonenal, one of the common lipid peroxidation by-products. ${ }^{52}$ The accumulation of NADH through ethanol metabolism promotes steatosis by stimulating the synthesis of fatty acids and opposing their oxidation. Through the reduction of pyruvate, elevated NADH levels also increase the levels of lactate, which stimulate collagen synthesis in myofibroblasts. ${ }^{2}$ The fatty liver is largely a result of the accumulation of acetyl $\mathrm{CoA}$, which in turn favours fatty acid synthesis and inhibits the Krebs cycle.

The energy per gram that ethanol provides exceeds that of carbohydrates and proteins, and could account, on average, for half an alcoholic's (heavy drinker's) kilojoule intake. ${ }^{2}$ Alcohol displaces nutrients like folate, thiamine and other vitamins, causing malnutrition. ${ }^{2}$ Inadequate intake and malabsorption due to gastrointestinal complications such as pancreatic insufficiency and impaired hepatic metabolism of nutrients causes secondary malnutrition. $^{2}$

Alcohol is also known to have a carcinogenic effect and is classified as a Group 1 carcinogen by the WHO..$^{53}$ Although some studies have failed to establish a direct relationship between alcohol and cancer there is a strong indication that it may act as a carcinogen by enhancing the carcinogenic effects of other chemicals like tobacco. Garro and Lieber ${ }^{54}$ report that alcohol enhances the ability of tobacco to stimulate tumour formation in rats. In humans, the risk for mouth, tracheal and oesophageal cancer is 35 times greater for individuals who both smoke and drink than for people who neither smoke nor drink. $^{55}$

Alcohol also has adverse effects on the human reproductive system. In males, alcohol causes atrophy of the semeninferous tubules, loss of sperm cells and increased production of abnormal sperm. ${ }^{56}$ Alcohol also has an adverse effect on testosterone synthesis and secretion, ${ }^{57,58}$ and is regarded as a testicular toxin. ${ }^{59}$ Alcohol also reduces the sperm quality (deterioration of sperm concentration, output and motility). ${ }^{60,61}$ In women, alcohol abuse is also associated with early menopause. ${ }^{62}$ The mechanisms underlying alcohol's disruption of the female menstrual cycle and anovulation are the temporary elevation of oestradio ${ }^{62}$ and testosterone, ${ }^{63}$ decreased levels of insulin-like growth factor 1 and reduced or absent pituitary luteinising hormone, respectively. ${ }^{64}$ Additionally, alcohol abuse causes a variety of reproductive disorders, ranging from irregular menstrual cycle ${ }^{64}$ to the absence of ovulation and infertility. ${ }^{62}$

\section{Teratogenic effects}

Alcohol is the most well-known teratogen, worldwide.$^{65}$ of the many substances of abuse (e.g., cocaine, heroin, marijuana), alcoholic beverages produce the most serious neurobehavioural effects in an unborn foetus. ${ }^{65}$ This ultimately burdens the economy and the health sector as a whole. It is already well known that alcohol consumption by pregnant women increases their chances of miscarriage or premature delivery, ${ }^{32}$ and the chances of the baby having low birth weight, congenital malformations $\mathrm{s}^{32,66,67}$ and foetal alcohol syndrome (FAS). ${ }^{66,68}$
Expression of FAS and the related disorders appears to be dependent on other component causes. ${ }^{69}$ Burd et a ${ }^{68}$ describe FAS as a multielement causal chain of interacting factors commonly including smoking, poor diet, poverty, low maternal education, heavy drinking, binge alcohol use, being unmarried, physical abuse and increased parity. The pattern and amount of alcohol consumed, timing of intake, developmental stage of the foetus at the time of exposure and sociobehavioural risk factors are pivotal determinants of birth outcome. ${ }^{69}$ The full FAS phenotype manifests in children whose mothers had a history of chronic, daily, heavy alcohol use or frequent, heavy, intermittent alcohol use (binge drinking). ${ }^{69}$

FAS can develop at any stage of the pregnancy, however, it is during the first trimester that the foetus is most vulnerable to alcohol damage. ${ }^{69}$ In some cases, alcohol exposure during pregnancy does not always lead to a full manifestation of the syndrome. The related disorders that develop are described as foetal alcohol effects, alcoholrelated birth defects, alcohol-related neurodevelopmental disorders or foetal alcohol spectrum defects. ${ }^{66,70-72}$ These manifestations of the syndrome are widely variable and are six to eight times more prevalent than full-blown FAS. ${ }^{70}$

The mechanisms by which excess ethanol consumption results in a toxic effect on the developing foetus are becoming increasingly clear. $^{73}$ Ethanol and acetaldehyde both cross readily through the placenta, depriving the developing foetal brain of both nutrients and oxygen. When ethanol crosses the placenta, foetal blood ethanol rises until it reaches equilibrium with maternal blood ethanol concentrations. ${ }^{70}$ The harmful effects of alcohol in the foetus are, however, more pronounced than in the alcohol-consuming mother, as the foetus is smaller in comparison to the blood alcohol levels and its detoxification system is not yet developed. Hence the ethanol remains longer in the foetal blood, prolonging the damage to its system. ${ }^{73}$ Ethanol has also been shown to reduce neural cell progenation in the central nervous system of the developing foetus and cause cell death by apoptosis. ${ }^{70}$ Acetaldehyde is also highly toxic to the developing foetus. Acetaldehyde is implicated in impairing DNA methylation, resulting in intra-uterine growth retardation, and hence lower birth weight and height, facial feature abnormalities (underdeveloped maxillary region, small fissures between the lids of the eyes); neurodevelopmental abnormalities, such as microcephaly; congenital abnormalities of the joints and heart; and persistent mental retardation. ${ }^{32}$

\section{Discussion and conclusion}

Metabolic changes associated with alcohol abuse ultimately lead to a number of biological health hazards as mentioned. Ingestion of alcohol during pregnancy can have severe effects on the developing foetus. Over time, alcohol abuse has become a major public health concern, and there is an increasing awareness that alcohol-related problems constitute serious problems for not only individuals, but also families, communities and economies. This pattern of irresponsible drinking in South Africa has increased public health and social problems, making the reduction of alcohol intake a priority for policy 
makers. There is, therefore, an urgent need to make a paradigm shift with regards to policies on alcohol use. Major problems that current policy makers face are (a) how to accurately quantify whether drinking patterns in a particular community are comparatively heavy, thus exacerbating health and psycho-socioeconomic problems, and (b) how to curb or overcome dangerous drinking patterns when they arise.

The WHO has recently stated that alcohol consumption is one of the leading causes of death worldwide and that intakes are increasing alarmingly in developing countries. ${ }^{6}$ According to the database of the WHO, fewer South Africans drink compared to people in 44 other countries. What is disturbing, however, is the pattern of drinking in South Africa; those reported to drink consume huge amounts of alcohol (20 litres of absolute alcohol per drinker per year). The observed pattern of binge drinking in about a third of South African drinkers is of serious concern. ${ }^{74,75}$ Alcohol misuse and abuse in South Africa is responsible for at least half of the 14000 annual reported road deaths. It is also known that this misuse is associated with crime ${ }^{76}$ violence, high sexual risk behaviour, family disruption, and a host of individual and societal problems. ${ }^{75}$ Binge drinking also results in a loss of the cardio-protective effects associated with alcohol, and an increase in micronutrient deficiencies, ${ }^{77}$ both of which are highly prevalent in the South African population. ${ }^{78}$ The observed pattern of drinking among South Africans can also lead to alcohol dependency and addiction, further exacerbating this problem. South Africans are somewhat prone to developing alcohol-related problems, largely due to the increasing economic hardships that usually accompany alcohol abuse.

The causal relationship between poverty and alcohol abuse can be compared to that of the egg and the chicken: which one comes first? The following results were obtained in a study that investigated the short- and long-term effects of poverty and unemployment on alcohol abuse using structural equation modelling to better understand the observed conflicting relationships among them: (a) increased poverty causes increased alcohol use and alcohol problems, and (b) recent unemployment decreases alcohol use while longer unemployment increases it. It was concluded that the effect of unemployment on alcohol abuse changes direction with time, and thus both crosssectional and longitudinal data are required to assess any meaningful relationship between them. ${ }^{79}$ Thus unemployment and poverty could be the leading causes of alcohol abuse in South Africa, since these two variables investigated are high in this sub-Saharan country.

The "French paradox" is a phenomenon that describes the low incidence of CVD in France, despite a general dietary pattern high in saturated fats. ${ }^{80}$ Several factors have been proposed to explain possible mechanisms by which alcohol could reduce CVD and atherosclerosis. ${ }^{81-84}$ These include the effects of low/moderate alcohol consumption on lipid and lipoprotein profiles, haemostatic function, the cardiovascular system, insulin sensitivity, homocysteine and oestrogen levels. ${ }^{85}$ Although the beneficial effects of moderate alcohol consumption remain stimulating, the levels of alcohol abuse among South African drinkers are of serious concern. Conclusively, more research is needed, particularly for this African population, to determine whether the French paradox is also applicable to this population before promoting the health benefits of moderate alcohol intake. The health hazards pertaining to this population also need to be weighed by policy makers, to assist them in their efforts to try to devise a comprehensive strategy to overcome abuse and dependency, while still retaining the attributed health benefits from alcohol consumption.

The final guideline proposed by the Food-Based Dietary Guidelines Work Group in 2001 is "If you drink alcohol, drink sensibly", and this addresses the use of alcohol in South Africa. ${ }^{32}$ However, considering the current abuse of alcohol in South Africa, this guideline might need to be re-examined. Currently, total abstinence from alcohol may be the only solution for this country in crisis, but the applicability of such a goal could be far-fetched and probably impossible to attain. Banning alcohol will surely lead users to turning to ingenious, exploitative and criminal methods of obtaining alcohol-containing beverages, ${ }^{32}$ and will increase the number of people brewing homemade alcohol concoctions. Therefore, the solution seems to be in educating the public to drink moderately or sensibly.

\section{References}

1. World Health Organization. Global status report on alcohol. Department of Mental Health and Substance Abuse. Geneva: WHO; 2004.

2. Lieber CS. Alcoholic fatty liver: its pathogenesis and mechanism of progression to inflammation and fibrosis. Alcohol 2004;34:9-19.

3. Caballeria J. Current concepts in alcohol metabolism. Ann Hepatol 2003;2:60-68.

4. Lieber CS. Metabolism of alcohol. Clin Liver Dis 2005;9:1-35.

5. Lieber CS. Ethanol metabolism, cirrhosis and alcoholism. Clin Chim Acta 1997;257:59-84.

6. World Health Organization. WHO guidelines for monitoring alcohol consumption and harm. Department of Mental Health and Substance Abuse. Geneva: WHO, 2000.

7. Arteel GE. Oxidants and antioxidants in alcohol-induced liver disease. J Gastroenterol 2003;124:778-90

8. Ericksson CJ. The role of acetaldehyde in the actions of alcohol (update 2000). Alcohol Clin Exp Res 2001;25:15-32.

9. Salaspuro M. Epidemiological aspects of alcoholic liver disease, ethanol metabolism and pathogenesis of alcoholic liver injury. 2nd edition. Oxford: Oxford University Press; 1999:1157-78.

10. Domschke S, Domschke W, Lieber CS. Hepatic redox state: attenuation of the acute effects of ethanol induced by chronic ethanol consumption. Life Sci 1974;15:1327-34.

11. Lieber CS. Hepatic metabolic and toxic effects of ethanol: 1991 update. Alcohol Clin Exp Res $1991 ; 15: 573-92$

12. Lieber CS, Decarli LM. Hepatic microsomal ethanol oxidising system: in vitro characteristics and adaptative properties in vivo. J Biol Chem 1970;245:2505-12.

13. Dupont I, Lucas D, Clot P, Menez C, Albano E. Cytochrome P4502E1 inducibility and hydroxyethyl radical formation among alcoholics. J Hepatol 1998;28:64-71

14. Nieto N, Friedman SL, Greenwel P, Cederbaum Al. CYP2E1-mediated oxidative stress induces collagen type 1 expression in rat hepatic stellate cells. Hepatology 1999;30:987-96.

15. Handler JA, Thurman RG. Redox interactions between catalase and alcohol dehydrogenase pathways of ethanol metabolism in perfused rat lives. J Biol Chem 1990;265:1510-15.

16. Hernandez-Munoz R, Caballeria J, Baraona, E, Uppal R, Greenstein R, Lieber CS. Human gastric alcohol dehydrogenase: Its inhibition by $\mathrm{H} 2$-receptor antagonists and its effect on the bioavailability of ethanol. Alcohol Clin Exp Res 1990;14:946-50.

17. Moreno A, Pares X. Purification and characterization of a new alcohol dehydrogenase from the stomach. J Biol Chem 1991;266:1128-33.

18. Yin SJ, Wang MF, Liao CS. Identification of a human stomach alcohol dehydrogenase with distinctive kinetic properties. Biochem Int 1990;22:829-35.

19. Julkunen RJH, Dipadova C, Lieber CS. First pass metabolism of ethanol: a gastrointestinal barrier against the systemic toxicity of ethanol. J Life Sci 1985;37:567-73.

20. Dohmen $\mathrm{K}$, Baraona $\mathrm{E}$, Ishibashi $\mathrm{H}$, et al. Ethnic differences in gastric sigma alcohol dehydrogenase activity and ethanol first pass metabolism. Alcohol Clin Exp Res 1996;20:1569-76.

21. Caballeria J, Frezza M, Hernandez-Munoz R, et al. The gastric origin of the first-pass metabolites of ethanol in humans: effect of gastrectomy. J Gastroenterol 1989;97:1205-09.

22. Caballeria J. First pass metabolism of ethanol: its role as a determinant of blood alcohol levels after drinking. J Hepatogastroenterol 1992;39:62-6. 
23. Jokelainen K, Siitonen A, Jousimies-Somer, H, Nosova T, Heine R, Salaspuro M. In vitro alcoho dehydrogenase-mediated acetaldehyde production by aerobic bacterial representing the normal colonic flora in man. Alcohol Clin Exp Res 1996;20:967-72.

24. Salaspuro M. Bacteriocolonic pathway for ethanol oxidation. Ann Med 1996;28:195-200.

25. Frezza M, Di Padova C, Pozzato G, Terpin M, Baraona E, Lieber CS. High blood alcohol levels in women. The role of decreased gastric alcohol dehydrogenase activity and first-pass metabolism. N Engl J Med 1990;322:95-9.

26. Yin SJ, Liao CS, Wu CW, et al. Human stomach alcohol and aldehyde dehydrogenases: comparison o expression pattern and activities in alimentary tract. Gastroenterology 1997;112:766-75.

27. Seitz HK, Egerer G, Simanowski U.A, et al. Human gastric alcohol dehydrogenase activity: effect of age gender and alcoholism. Gut 1993;34:1433-7.

28. Laposata EA, Lange LG. Presence of nonoxidative ethanol metabolism in human organs commonly damaged by ethanol abuse. Science 1986;231:497-9.

29. Kalant, H. Pharmacokinetics of ethanol: absorption, distribution and elimination. In: Begleiter $H$, Kissin B, eds: The pharmacology of alcohol and alcohol dependence. New York: Oxford University Press USA; 1996:15-58.

30. Ericksson C.JP. Human blood acetaldehyde during ethanol oxidation (update 1982). Pharmacol Biochen Behav 1983:18:141-50

31. Carmichael FJ, Saldivia V, Varghese GA, Israel Y, Orrego H. Ethanol-induced increase in portal blood flow. Role of acetate and A1 and A2 adenosine receptors. Am J Physiol 1988;2225:417-23.

32. Van Heerden IV, Parry CDH. If you drink alcohol, drink sensibly. S Afr J Clin Nutr 2001;14(3):S71-7.

33. McIntosh C, Chick J. Alcohol and the nervous system. J Neurol Neurosurg Psychiatry 2004;75:16-21.

34. Homewood J, Bond NW. Thiamine deficiency and Korsakoff's syndrome: failure to find memory impairments following non-alcoholic Wernicke's encephalopathy. Alcohol 1999;19(1):75-84.

35. Aminoff, M.J., Greenberg, D.A., Simon, R.P. Clinical Neurology. 6th edition. New York: Lange Medica Books/McGraw-Hill; 2005:113.

36. Thomson AD, Cook CH, Touquet R, Henry JA. The Royal College of Physicians' report on alcohol Guidelines for managing Wernick's encephalopathy in the accident and emergency department. Alcohol Alcohol 2002;37(6):513-21.

37. Monforte R, Estruch R, Valls-Solé J, Nicolás J, Villalta J, Urbano-Marquez A. Autonomic and periphera neuropathies in patients with chronic alcoholism. A dose-related toxic effect of alcohol. Arch Neuro 1995;52(1):45-51.

38. Urbano-Marquez A, Estruch R, Navarro-Lopez F, Grau JM, Mont L, Rubin E. The effects of alcoholism on skeletal and cardiac muscle. N Engl J Med 1989;320(7):409-15.

39. Wiese JG, Shlipak MG, Browner WS. The alcohol hangover. Ann Intern Med 2000;132(11):897-902.

40. Schuppan D, Atkinson J, Ruehl M, Rieken E.0. Alcohol and liver fibrosis-pathobiochemistry and treatment. Z Gastroenterol 1995;33:546-50.

41. Lieber CS. Alcoholic liver injury: pathogenesis and therapy in 2001. Pathol Biol (Paris) 2001;49:738-52.

42. Wang JH, Batey RG, George J. Role of ethanol in the regulation of hepatic stellate cell function. World J Gastroenterol 2006;12:6926-32

43. Tsukamoto H, Lu SC. Current concepts in the pathogenesis of alcoholic liver injury. FASEB 2001;15:1335-49.

44. Matsuoka M, Zhang MY, Tsukamoto H. Sensitization of hepatic lipocytes by high-fat diet to stimulatory effects if Kupffer cell-derived factors: implication in alcoholic liver fibrogenesis. Hepatology 1990;11:173-82.

45. Tsukamoto H, Cheng S, Blanner WS. Effects of dietary polyunsaturated fat on ethanol-induced Ito cell activation. Am J Physiol 1996;270:581-6.

46. Casini A, Cunningham M, Rojkind M, Lieber CS. Acetaldehyde increases procollagen type 1 and fibronectin gene transcription in cultured rat fat-storing cells through a protein synthesis dependent mechanism. Hepatology 1991;13:758-65.

47. Anania FA, Potter JJ, Rennie-Tankersley L, Mezey E. Activation by acetaldehyde of the promoter of the mouse alpha 2 (1) collagen gene when transfected into rat activated stellate cells. Arch Biochem Biophys 1996;331:187-3

48. Chen A. Acetaldehyde stimulates the activation of latent transforming growth factor-beta1 and induces expression of the type 2 receptor of the cytokine in rat cultured hepatic stellate cells. Biochem 2002;368:683-93.

49. Cahill A, Cunningham CC, Adachi M, et al. Effects of alcohol and oxidative stress on liver pathology: the role of the mitochondria. Alcohol Clin Exp Res 2002;26:907-15.

50. Nieto N, Friedman SL, Cederbaum Al. Stimulation and proliferation of primary rat hepatic stellate cells by cytochrome P4502E1 derived reactive oxygen species. Hepatology 2002;35:62-73.

51. Aroor AR, Shukla SD. MAP kinase signalling in diverse effects of ethanol. Life Sci 2004; 74:2339-64.

52. Parola M, Robino G, Marra F, et al. HNE interacts directly with JNK isoforms in human hepatic stellate cells. J Clin Invest 1998;102:1942-50.

53. International Agency for Research on Cancer. Monographs on the evaluation of carcinogenic risks to humans: alcohol drinking summary of data reported and Evaluation. Lyon: IARC Press; 1988:Vol 44

54. Garro AJ, Lieber CS. Alcohol and cancer. Annu Rev Pharmacol Toxicol 1990;30:219-49.

55. Blot WJ, Mclaughlin JK, Winn DM, et al. Smoking and drinking in relation to oral and pharyngeal cancer Cancer Res 1988;48:3282-7.

56. Bennet HS, Baggenstgors AH, Butt HR. The testes, breast and prostate in men who die of cirrhosis of liver Am J Clin Pathol 1950:20:814-28.
57. Ylikahri R, Huttunen M, Harkonen M, Adlercreutz H. Hangover and testosterone. BMJ 1974;2:445

58. Mendelson JM, Ellingboe J, Mello NK, Kuehnli J. Effects of alcohol on plasma testosterone and luteinizing hormone levels. Alcohol Clin Exp Res 1978:2:255-8.

59. Van Thiel DH, Gavaler JS, Lester R, Goodman MD. Alcohol induced testicular atrophy: an experimental model for hypogonadism occurring in chronic alcoholic man. Gastroenterology 1975;69:326-32.

60. Kucheria K, Saxena R, Mohan D. Semen analysis in alcohol dependence syndrome. Andrologia 1985;17:558-63.

61. Brzek A. Alcohol and male fertility (preliminary report). Andrologia 1987;19:32-6.

62. Mello NK, Mendelson JH, Teoh SK. Overview of the effects of alcohol on the neuroendocrine function in women. In: Zakhari S, ed. Alcohol and the endocrine system. National Institute on Alcohol Abuse and Alcoholism, Research Monograph № 23. NIH Pub, № 93-3533. Bethesda, MD: National Institutes of Health; 1993: 139-69

63. Sarkola T, Adlercreutz H, Heinonen S, Von der Pahlen B, Eriksson C.JP. The role of the liver in the acute effect of alcohol on androgens in women. J Clin Endocrinol Metab 2001;86:1981-5.

64. Emanuele MA, Wezeman F, Emanuele NV. Alcohol's effects on female reproductive function. Alcoho Health Res World 2002;26:274-81.

65. Leonardson GR, Loudenburg R. Risk factors for alcohol use during pregnancy in a multistate area Neurotoxicol Teratol 2003;25:651-8.

66. Hoyme HE, May PA, Kalberg W0, et al. A practical clinical approach to diagnosis of foetal alcohol spectrum disorders: clarification of the 1996 Institute of Medicine Criteria. Paediatrics 2005;115(1):39-47.

67. Shankaran S, Das A, Baur CR, et al. Association between patterns of maternal substance use and infant birth weight, length, and head circumference. Paediatrics 2004;114(2):226-34

68. Burd L, Martsolf J, Klug MG, O'Connor E, Peterson M. Prenatal alcohol exposure assessment: multiple embedded measures in a prenatal questionnaire. Neurotoxicol Teratol 2003;25:675-9. (b)

69. 0'Leary CM. Foetal alcohol syndrome: diagnosis, epidemiology, and developmental outcomes. J Paediatr Child Health 2004:40:2-7.

70. Burd L, Cotsonas-Hassler TM, Martsolf JT, Kerbeshian J. Recognition and management of foetal alcoho syndrome. Neurotoxicol Teratol 2003:25:681-8. (a)

71. Struck J. Four-State FAS Consortium: model for program implementation and data collection Neurotoxicol Teratol 2003:25:643-9.

72. Walsh Dotson J, Henderson D, Magraw M. A public health program for preventing foetal alcoho syndrome among women at risk in Montana. Neurotoxicol Teratol 2003;25:757-61.

73. Whitney EN, Rolfes SR. Understanding nutrition. 9th edition. Belmont, CA: West/Wadsworth USA 2001:695-7.

74. Rehm J, Rehn N, Room R, et al. The global distribution of average volume of alcohol consumption and patterns of drinking. Eur Addict Res 2003;9:147-56.

75. Parry CD, Plüddemann A, Steyn K, Bradshaw D, Norman R, Laubscher R. Alcohol use in South Africa: findings from the first demographic and health survey (1998). J Stud Alcohol 2005;66 (1):91-7.

76. Human Sciences Research Council of South Africa. HSRC research findings: drug and alcohol intake's contribution to crime. Media release, Pretoria: HSRC; 1996.

77. McKee M. Alcohol in Russia. Alcohol Alcohol. 1999;34(6):824-9.

78. Vorster HH. The emergence of cardiovascular disease during urbanization of Africans. Public Health Nut 2002;5(1A):239-43

79. Khan S, Murray RP, Barnes GE. A structural equation model of the effect of poverty and unemployment on alcohol abuse. Addict Behav 2002;27(3):405-23.

80. De Gaetano G, Di Castelnuovo A, Donati MB, lacoviello L. The Mediterranean lecture: wine and thrombosis-from epidemiology to physiology and back. Path Haem Throm; 33(5/6):466-71.

81. Grobbee DE, Rimm EB, Keil U, Renaud S. Alcohol and the cardiovascular system. In: Macdonald I, ed. Health issues related to alcohol consumption. London: Blackwell Science Britain; 1999:125-79.

82. Rotondo S, Di Castelnuovo A, De Gaetano G. The relationship between wine consumption and cardiovascular risk, from epidemiological evidence to biological plausibility. Ital Heart J 2001;2:1-8.

83. Srivastava LM, Vasisht S, Agarwal DP, Goedde HW. Relation between alcohol intake, lipoproteins and coronary heart disease: the interest continues. Alcohol Alcohol 1994;29:11-24.

84. Goldberg DM, Soleas GJ. Beverage alcohol consumption as a negative risk factor for coronary heart disease, biochemical mechanisms. In: Agarwal DP, Seitz HK, eds. Alcohol in health and disease. New York: Marcel Dekker USA; 2001:547-72.

85. Agarwal DP. Cardioprotective effects of light-moderate consumption of alcohol: a review of putative mechanisms. Alcohol Alcohol 2002:37(5):409-15. 